\title{
Effect van onderwijs over knie-, enkel- en onderbeen- problemen bij eerstejaars huisartsen in opleiding (haio's)
}

\author{
F. Baarveld, P. Boendermaker, G. Heule, B. Kollen
}

\section{Samenvatting}

Inleiding: Er wordt onvoldoende aandacht besteed in de medische basisopleiding en de vervolgopleiding tot huisarts aan de in de huisartspraktijk veel voorkomende klachten van het houdings- en bewegingsapparaat. Door eerstejaars huisartsen in opleiding (haio's) bloot te stellen aan specifiek onderwijs hierover wordt gepoogd hun kennis te vergroten. Dit onderzoek beoogt de effectiviteit van dit onderwijs inzichtelijk te maken.

Methode: De kennis van 135 eerstejaars haio's uit 2002, 2003 en 2004 werd getoetst voorafgaande aan (meting 1), direct aansluitend aan (meting 2) en drie maanden na het onderwijs (meting 3).

Resultaten: Het percentage van goede antwoorden op de toetsen na het onderwijs is hoger dan daarvoor en is het hoogst bij de tweede meting. Een goede score is niet afhankelijk van geslacht, leeftijd, sportervaring en interesse in de sportgeneeskunde van de deelnemers. Van de drie jaargebonden cohorten scoort de jaargroep haio's uit 2003 verreweg het hoogst op de drie toetsen. Op het evaluatieformulier geeft deze jaargroep aan minder te hebben geleerd en minder nieuws te hebben gehoord dan de overige jaargroepen.

Conclusie: Bij deze groepen eerstejaars haio's heeft het onderwijs een gunstig effect op het kennisniveau van de knie-, enkel- en onderbeenproblematiek. Bovendien is dit effect, zij het in mindere mate, nog steeds aanwezig drie maanden nadien. Geen duidelijke verklaring werd gevonden voor het verschil in prestaties tussen de jaargroepen. Een goede score op de kennistoets wordt niet beïnvloed door geslacht, leeftijd, interesse in de sportgeneeskunde en eigen sportervaring. (Baarveld F, Boendermaker P, Heule G, Kollen B. Effect van onderwijs over knie-, enkel- en onderbeenproblemen bij eerstejaars huisartsen in opleiding (haio's).

Tijdschrift voor Medisch Onderwijs 2005;24(6):245-249.)

\section{Inleiding}

Klachten met betrekking tot het houdingsen bewegingsapparaat vormen, op respiratoire problemen en huidaandoeningen na, de meest voorkomende reden om een huisarts te consulteren. ${ }^{1}$ Meer dan $70 \%$ van de bevolking heeft wel eens klachten van het houdings- en bewegingsapparaat gehad, terwijl 37\% hier nog steeds klachten van heeft. ${ }^{2}$ Na rugklachten vormen knieklachten de belangrijkste groep. ${ }^{3}$ Ondanks de hoge frequentie, waarin problematiek van het houdings- en bewegingsapparaat voorkomt in de huisartspraktijk, wordt hierover relatief weinig onderwezen. Dit geldt zowel voor de medische basisopleiding als de driejarige vervolgopleiding tot huisarts. De noodzaak van en behoefte aan aanvullende training en intensiever onderwijs op dit gebied is de laatste jaren veelvuldig gerapporteerd. ${ }^{4-8}$

In Groningen wordt sedert 1994 in de huisartsopleiding wel specifieke aandacht geschonken aan dit onderdeel van het brede vakgebied huisartsgeneeskunde. Er wordt aan alle eerstejaars huisartsen in opleiding (haio's) een zogenaamde 'bewegingsdriedaagse' aangeboden. Gedurende drie opeenvolgende dagen krijgen de haio's onderwijs op het gebied van het 
houdings- en bewegingsapparaat, zowel theoretisch als praktisch. Dit onderwijs wordt verzorgd door specialisten op het gebied van het houdings- en bewegingsapparaat (sportartsen) en huisartsen met bijzondere affiniteit tot het onderwerp.

Ten einde het effect van een deel (de tweede dag) van deze driedaagse inzichtelijk te maken, wordt in dit onderzoek gepoogd een antwoord te vinden op de volgende vragen:

1. Wordt het kennisniveau van de knie-, enkel- en onderbeenproblematiek gunstig beïnvloed door het specifieke onderwijs en beklijft deze kennis?

2. Wordt het percentage goed beantwoorde vragen op de kennistoets van het houdings- en bewegingsapparaat beïnvloed door geslacht, leeftijd, sportervaring, interesse in sportgeneeskunde of opleidingsjaar?

\section{Materiaal en Methode}

\section{Studiedesign}

Cohortonderzoek, waarin middels een schriftelijk meetinstrument kennis werd getoetst voorafgaande aan en na afloop van de dag waarop het onderwijs over knie-, onderbeen- en enkelproblematiek gegeven werd, en drie maanden nadien. Deze tweede onderwijsdag van de bewegingsdriedaagse is drie jaar op dezelfde wijze geprogrammeerd en door dezelfde docenten gegeven. Afname vond plaats onder vergelijkbare condities.

\section{Studiedeelnemers}

Alle eerstejaars haio's uit 2002, 2003 en 2004, die deelnamen aan de tweede dag van de bewegingsdriedaagse van de huisartsopleiding te Groningen, participeerden in het onderzoek.

\section{Schriftelijke toets}

Het meetinstrument is samengesteld uit 25 vragen, elk bestaande uit drie antwoordmogelijkheden (goed/weet niet/fout), identiek aan de landelijke huisartsgeneeskundige kennistoets die alle haio's twee keer per jaar tijdens hun opleiding maken. De vragen zijn onder te verdelen in 15 kennisvragen en 10 kennis-over-vaardigheden vragen en hebben betrekking op het gegeven onderwijs, inclusief klinische vaardigheden, over aandoeningen van knie, enkel en onderbeen. Het betreft een korte hanteerbare toets vooraf en na afloop van het onderwijs, bestaande uit stamvragen.

De eerste meting werd voorafgegaan door enkele algemene vragen die betrekking hebben op de demografische kenmerken van de deelnemers, zoals geslacht, leeftijd en interesse in sportgeneeskunde en eigen sportervaring.

\section{Statistische analyse}

De aantallen goed gescoorde en 'weet niet'-antwoorden werden omgerekend in percentages en vervolgens statistisch bewerkt met behulp van ANOVA- en MANOVA-toetsen. Er werd tweezijdig getoetst bij een significantieniveau van vijf procent. De statistische analyses werden uitgevoerd in SPSS-12.

\section{Resultaten}

In totaal zijn 135 eerstejaars haio's van drie jaargroepen (2002, 2003 en 2004) geïncludeerd. De gemiddelde leeftijd van de respondenten verschilde significant per jaar: 41 in 2002, 38 in 2003 en 32 in 2004 $(\mathrm{F}=13,752$; $\mathrm{p}=0.000) .115$ van de 135 deelnemende haio's hebben alle toetsen volbracht. Per meting beschouwd, ontbraken er 2 toetsen bij de eerste meting $(1,5 \%), 6$ toetsen bij de tweede meting $(4,4 \%)$ en 13 toetsen bij de derde meting $(9,6 \%)$. 18 respondenten gaven aan geen interesse in sportgenees- 
kunde te hebben $(15,7 \%), 71$ respondenten waren enigszins geïnteresseerd $(61,7 \%)$ en 26 respondenten hadden veel interesse in de sportgeneeskunde $(22,6 \%)$. Actief sporten in competitieverband (nu of in het verleden) wordt door 50 respondenten aangegeven (44,6\%), 40 respondenten doen (of hebben gedaan) aan recreatiesport (35,7\%), terwijl 22 respondenten nauwelijks sporten $(19,1 \%)$. Drie haio's hebben zich over het laatste onderwerp niet geuit.

\section{Schriftelijke toets}

Het percentage goed beantwoorde vragen staat vermeld in tabel 1 . Hierbij blijkt er sprake te zijn van een significante verandering in het verloop van de resultaten van de metingen $(\mathrm{F}=122,771 ; \mathrm{p}=.000)$ met gemiddeld een hoger percentage goede antwoorden bij de schriftelijke toets behorend bij de tweede meting. De derde meting blijft echter wel boven het niveau van de basismeting. Dit verloop in de tijd is vooral gekromd (resp. $\mathrm{F}=202,951 ; \mathrm{p}=.000$ ). Er is tevens een significant verschil tussen de metingen onderling (meting 1-2, meting 1-3 en meting 2-3) gevonden ( $\mathrm{p}=.000)$.

Een goede score op de toetsen wordt niet beïnvloed door geslacht $(\mathrm{F}=1,657$; $\mathrm{p}=.201)$, leeftijd $(\mathrm{F}=.401 ; \mathrm{p}=.752)$, sportervaring $(\mathrm{F}=2,060 ; \mathrm{p}=.132)$ of interesse in de sportgeneeskunde $(\mathrm{F}=1,343 ; \mathrm{p}=.265)$. Een goede score is daarentegen wel afhankelijk van het jaar waarin de toets werd afgenomen $(\mathrm{F}=8,025 ; \mathrm{p}=.001)$ (tabel 1, figuur 1).
Figuur 1. Gemiddelde percentages van goed beantwoorde vragen, weergegeven per jaargroep.

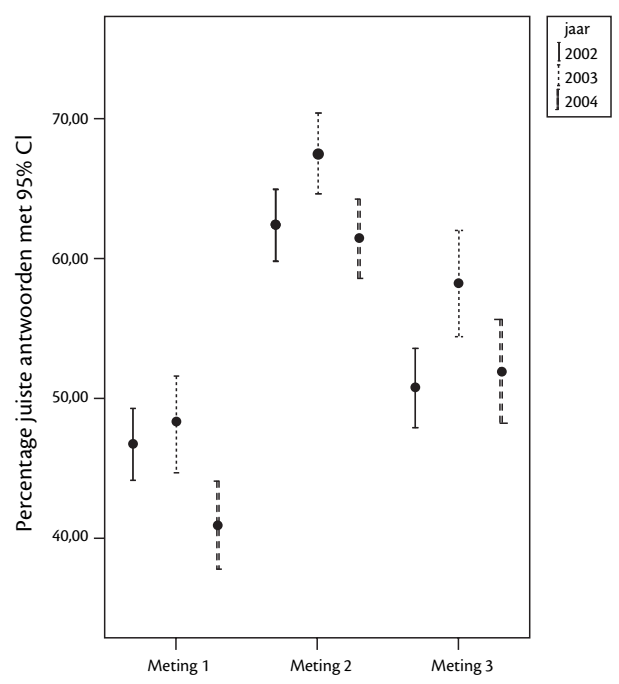

Bij de eerste meting is het percentage juiste antwoorden gemiddeld 15\% lager bij degenen met 'weet niet'-antwoorden ten opzichte van hen zonder 'weet niet'antwoorden. Bij de tweede meting is dit percentage $5 \%$ lager, terwijl dit percentage bij de derde meting $11 \%$ lager is.

\section{Discussie}

De basiskennis (op basis van de eerste meting) van de haio's met betrekking tot knie-, enkel- en onderbeenproblematiek is niet optimaal. Dat blijkt uit het frequente gebruik van de 'weet niet'-optie bij de

Tabel 1. Percentages goed beantwoorde vragen per meting voor de jaargroepen.

\begin{tabular}{lllllllll}
\hline \multirow{2}{*}{ Meting } & \multicolumn{2}{c}{$2002(\mathrm{n}=\mathbf{4 0})$} & \multicolumn{2}{c}{$2003(\mathrm{n}=\mathbf{4 1})$} & \multicolumn{2}{c}{$2004(\mathrm{n}=\mathbf{3 4})$} & \multicolumn{2}{c}{ Totaal $(\mathrm{n}=\mathbf{1 1 5})$} \\
\cline { 2 - 8 } & Gem. (\%) & SD $^{* *}$ & Gem. (\%) & SD & Gem. (\%) & SD & Gem. (\%) & SD \\
\hline 1 & 46,30 & 12,68 & 48,78 & 10,82 & 39,76 & 10,87 & 45,25 & 12,00 \\
2 & 62,10 & 08,59 & 67,51 & 09,97 & 61,41 & 08,91 & 63,83 & 09,53 \\
3 & 51,60 & 10,86 & 57,95 & 11,84 & 51,76 & 11,44 & 53,91 & 11,68 \\
\hline
\end{tabular}

*Gem. $=$ gemiddelde ${ }^{* *} S D=$ standaarddeviatie. 
beantwoording van deze vragen door de respondenten. Dit komt overeen met de constatering van veel onderzoekers, dat medisch studenten te weinig onderwijs krijgen over houdings- en bewegingsapparaatproblematiek. ${ }^{4-8}$ De uitkomsten van de metingen na de onderwijsinterventie laten een significante verbetering zien ten opzichte van die van de voormeting. Het percentage goed beantwoorde vragen is het hoogst bij de tweede meting, neemt vervolgens weer af bij de derde meting, maar overtreft desondanks die van de eerste meting. Dit fenomeen is eerder beschreven en lag daarom in de lijn der verwachting. 59 Deze observatie suggereert evenwel dat het effect van de onderwijsinterventie niet van voorbijgaande aard is. 5

Een goede score op de toetsen is niet afhankelijk van geslacht, leeftijd, sportervaring of interesse in de sportgeneeskunde. De verwachting bij aanvang dat haio's met interesse op sportgeneeskundig gebied en/of met sportervaring een hogere toetsscore zouden halen, kon niet aangetoond worden. Er werd echter wel een significant verschil in het percentage goed beantwoorde vragen tussen de drie verschillende jaargroepen gevonden. Omdat de opzet van de bewegingsdriedaagse en de docenten hetzelfde zijn gebleven in de afgelopen jaren, is het niet waarschijnlijk dat het onderwijs tijdens de bewegingsdriedaagse een rol heeft gespeeld bij de gevonden verschillen. Mogelijk is dit te verklaren door, niet onderzochte, andere factoren, zoals verschillen in jaargebonden haio-specifieke eigenschappen. Zoals besproken gaven de haio's uit 2003 aan minder te hebben geleerd en minder nieuws te hebben gehoord. Een en ander is mogelijkerwijs het gevolg van hun hoger kennisniveau. Hun scores waren verreweg het hoogst bij alle toetsen. Hoewel er sprake was van significante verschillen in haio-leeftijd tussen de jaargroepen, bleek leeftijd geen relatie te vertonen met het percentage goed beantwoorde vragen.

Dit onderzoek biedt geen inzicht in de specifieke kenmerken van haio's die verantwoordelijk zijn voor een hoge 'weet niet'score bij al de drie toetsen. Interessant is de vraag in hoeverre er interuniversitaire haio-verschillen bestaan in kennisdeficiëntie en -acquisitie ten aanzien van dit onderwerp. Nader onderzoek kan hier wellicht inzicht in verschaffen. Dit prospectief cohortonderzoek was gebaseerd op herhaalde metingen bij een selecte groep haio-respondenten, gerekruteerd in de jaren 2002, 2003 en 2004. De uitkomsten van een dergelijk onderzoek zijn gevoelig voor allerlei vormen van vertekening, zoals bijvoorbeeld groei- en testeffecten, tussentijds extern voorval, selectieve uitval en recall bias. Voorts zijn van de gebruikte toetsen niet de klinimetrische eigenschappen bepaald. Als gevolg hiervan kan geen uitspraak worden gedaan over de interne consistentie, betrouwbaarheid en validiteit van het toegepaste meetinstrument.

\section{Conclusie}

Bij deze groep respondenten is gebleken dat het specifieke onderwijs een gunstige invloed heeft op de kennis van de knie-, enkel- en onderbeenproblematiek. Na de onderwijsinterventie scoorden de deelnemers hoger dan direct daarvoor. Tevens werd er een verschil in scores tussen de haio-jaargroepen waargenomen dat niet verklaard kan worden door leeftijd of mate van interesse in sportgeneeskunde en/of sportervaring. Een goede score op de kennistoets wordt niet beïnvloed door geslacht, leeftijd, interesse in de sportgeneeskunde en eigen sportervaring. 


\section{Literatuur}

1. Lisdonk EH van de, Bosch WJHM van den, Lagro-Janssen ALM, editors. Ziekten in de huisartspraktijk. $4^{\mathrm{e}}$ herziene druk. Maarssen: Elsevier Gezondheidszorg; 2003.

2. Vernec A, Shrier I. A teaching unit in primary care sports medicine for family medicine residents. Acad Med 2001;76:293-6.

3. Plas CG van der, Dingjan RA, Hamel A, Jonker JC, Postema PhJ, Smorenburg HAAJ, et al. Traumatische knieproblemen. NHG-standaard. Huisarts Wet 1998;41:296-300.

4. Buckler DG. General practitioners' training for, interest in, and knowledge of sports medicine and its organisations. Br J Sports Med 1999;33:360.

5. Hergenroeder AC. Pediatric residents' performance of ankle and knee examinations after an educational intervention. Pediatrics 2001;107:52.

6. Vergeer I. Family physicians and sports-injury care. Perceptions of coaches. Can Fam Physician 1997;43:1755-61.

7. Wiley JP, Strother RT, Lockyer JM. Sports medicine electives. Are they available in Canadian family medicine programs? Can Fam Physician 1993;39:1742-4.
8. Freedman KB. The adequacy of medical school education in musculoskeletal medicine. J Bone Joint Surg 1998;80:1421-7.

9. Lawry GV. Teaching a screening musculoskeletal examination: a randomised, controlled trial of different instructional methods. Acad Med 1999;74:199-201.

De auteurs:

Dr. F. Baarveld is verbonden aan de Disciplinegroep Huisartsgeneeskunde, afdeling Huisartsopleiding, Universitair Medisch Centrum Groningen.

Dr. P. Boendermaker is verbonden aan de Disciplinegroep Huisartsgeneeskunde, afdeling Huisartsopleiding, Universitair Medisch Centrum Groningen.

Mw. G. Heule studeert geneeskunde aan de Rijksuniversiteit Groningen.

Dhr. B. Kollen is werkzaam bij het Research Bureau van de Isala Klinieken te Zwolle.

\section{Correspondentieadres:}

Dr. Frank Baarveld, Rijksuniversiteit Groningen, Faculteit der Medische Wetenschappen, Disciplinegroep Huisartsgeneeskunde, Antonius Deusinglaan 1, 9713 AV Groningen, f.baarveld@med.umcg.nl.

\section{Summary}

Introduction: Medical education shows shortcomings regarding training in musculoskeletal disorders. In an attempt to improve this deficiency, a special training programme was offered to first year general practice (GP) trainees. The objective of this study was to test the effectiveness of this programme.

Method: The participants in this study were 135 first year GP trainees from the cohorts entering the programme in 2002, 2003 and 2004, respectively. A written test was administered before, immediately after and 3 months after the training programme to determine the participants' knowledge on knee, ankle and lower limb disorders.

Results: The test scores from the second and third measurements were significantly higher than those of the first. The percentage of correct answers was highest for the second measurement. A significant difference was observed between cohorts. The test scores were not related to gender, age, prior experience with sports and interest in sports medicine. The cohort starting in 2003 topped the scores, but also indicated to have benefited least from this special programme.

Conclusion: The training programme proved to be beneficial to the participants. Moreover, the improved knowledge on knee, ankle and lower limb disorders persisted after the programme. No clear explanation was found for the difference in scores between student cohorts. Outcome was not dependent upon gender, age, experience with sports and interest in sports medicine. (Baarveld F, Boendermaker P, Heule G, Kollen B. The effect of a training programme on knee, ankle and lower limb disorders among first year trainees in general practice. Dutch Journal of Medical Education 2005;24(6):245-249.) 